\title{
IMPACT OF THE CORONAVIRUS DISEASE-19 PANDEMIC ON ACUTE CARDIOVASCULAR EMERGENCIES IN A THIRD LEVEL CARDIOLOGY HOSPITAL: A CALL FOR ACTION
}

\author{
Jorge Gaspar-Hernández ${ }^{1}$, Diego Araiza-Garaygordobil ${ }^{1 *}$, Rodrigo Gopar-Nieto ${ }^{1}$, \\ Pablo Martínez-Amezcua ${ }^{2}$, and Alexandra Arias-Mendoza ${ }^{1}$ \\ ${ }^{1}$ Cardiovascular Critical Care Unit, Instituto Nacional de Cardiología Ignacio Chávez, Mexico City, Mexico; ${ }^{2}$ Department \\ of Epidemiology, Johns Hopkins Bloomberg School of Public Health, Johns Hopkins University, Baltimore, USA
}

\section{BACKGROUND}

The consequences of the coronavirus disease (COVID)-19 pandemic go beyond the number of cases and deaths attributed to severe acute respiratory syndrome (SARS)-coronavirus-2 infection. The overwhelmed health care systems and the strict social containment measures have had an impact on the threshold at which patients seek medical care for diseases other than COVID-19, including cardiovascular conditions. The previous studies have reported a decrease in the rate of hospitalizations for acute coronary syndromes, delay in seeking medical attention, and a decreased number of diagnostic and therapeutic procedures performed after the COVID-19 outbreak $^{1-3}$. Yet, whether the attention for other severe and time-sensitive acute cardiovascular conditions has been affected, which remains ill-defined. The aim of our study was to evaluate the change in emergency department (ED) admissions for nine major acute cardiovascular emergencies after the onset of the COVID-19 pandemic.

\section{METHODS}

We conducted a retrospective study that included consecutive adult patients aged $\geq 18$ years old, admitted to the ED of the study center for nine major acute cardiovascular emergencies, including acute pulmonary embolism, acute decompensated heart failure, acute coronary syndromes, tachy- and bradyarrhythmias, hypertensive emergencies, ischemic stroke, acute aortic syndromes, and endocarditis. The study center is a third level cardiovascular hospital that provides medical attention to first comers and referrals from the Mexico City metropolitan area (20.9 million inhabitants). Diagnoses were assessed from patients' medical records and based on pertinent clinical guidelines. ED admissions were aggregated in a weekly manner for the analysis. The pandemic period was defined as the 7-week period after the national COVID-19 emergency declaration in Mexico (March $30^{\text {th }}-$ May $16^{\text {th }}, 2020$ ). Two controls were used: a 12-week pre-pandemic period (January $5^{\text {th }}$-March 29th 2020 ) and a 2019 historical matched
*Corresponding author:

Diego Araiza-Garaygordobil

E-mail: dargaray@gmail.com
Received for publication: 15-07-2020

Approved for publication: 30-07-2020

DOI: $10.24875 /$ RIC.20000349

0034-8376 / (c) 2020 Revista de Investigación Clínica. Published by Permanyer. This is an open access article under the CC BY-NC-ND license (http://creativecommons.org/licenses/by-nc-nd/4.0/). 
Figure 1. Weekly average of admissions for acute cardiovascular emergencies at the emergency department. Dashed line represents the national coronavirus disease-19 emergency declaration. Highlighted in yellow is the study pandemic period.

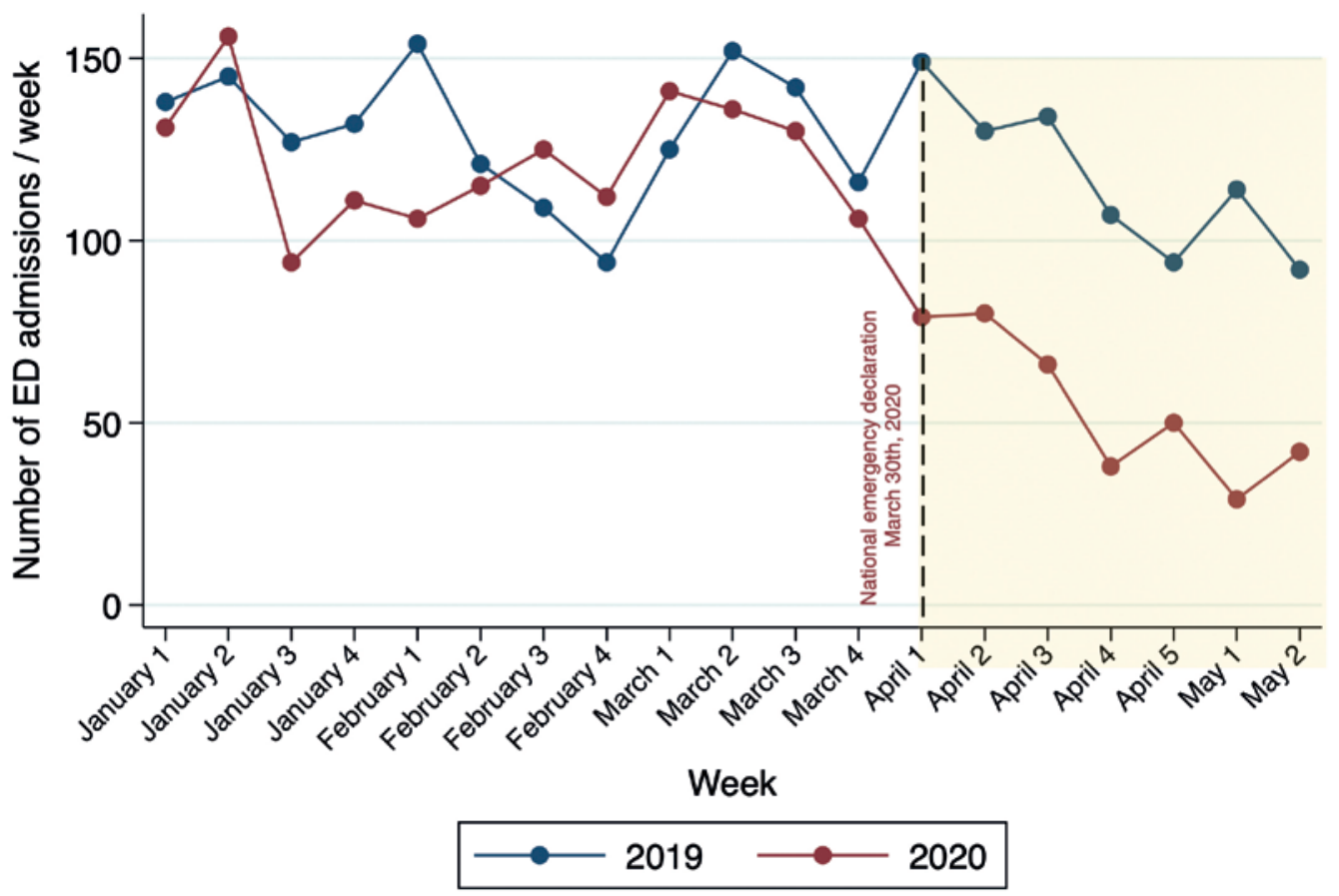

Acute cardiovascular emergencies

control 7-week period (March 30th-May 16 th, 2019 ). The protocol complies with the principles of the Declaration of Helsinki, and the final database supporting the findings of the present study is available from the corresponding author on reasonable request.

\section{RESULTS}

During the 7-week study period, we found a 55\% reduction in mean weekly acute cardiovascular emergencies compared with the 12-week period preceding the pandemic (121/week pre-pandemic vs. 55/week pandemic period; difference: $66.0,95 \%$ confidence intervals [Cl]: [48.3-85.7], $p<0.0001$ ) (Fig. 1). Similarly, we identified a $45.5 \%$ reduction when comparing the study period with the matched 2019 historical control (117/week historical control vs. 55/ week pandemic period; difference 62.2, 95\% $\mathrm{Cl}$ : 37.9-86.5], $\mathrm{p}<0.0001$ ). The reduction was observed in all nine diagnoses, ranging from $-12 \%$ for bradyarrhythmias to $-93 \%$ for acute endocarditis. These reductions were accompanied by a decrease in the number of patients seen in the outpatient clinic, in the total number of hospital admissions, and in the occupation of intensive cardiovascular units (Table 1 ).

\section{DISCUSSION}

Previous infectious outbreaks have been associated with a decrease in the healthcare offer and demand for acute conditions. A retrospective population-based study during the 2003 SARS outbreak showed a $37 \%$ decrease reduction in high-acuity visits to EDs in the metropolitan area of Toronto ${ }^{4}$. Another report showed major changes in cardiac care during the outbreak, including a substantial decrease in cardiac catheterizations $^{5}$. Both studies acknowledge that the restrictions in the use of health care services may affect the access for some potentially seriously ill patients.

The present study adds to the medical literature that the care of other cardiovascular emergencies, in addition to acute coronary syndromes, has changed during the COVID-19 pandemic, and the consequences of this phenomenon remain to be seen. Due to the worldwide spread of the COVID-19 pandemic, this 
Table 1 . Shows relative reductions in outpatient visits, hospitalizations, and cardiovascular ICU occupation

\begin{tabular}{|c|c|c|c|c|}
\hline & $\begin{array}{l}\text { Historic control, } \\
\text { March } 30^{\text {th }}-\text { May } 16^{\text {th }} \\
2019\end{array}$ & $\begin{array}{c}\text { Pre-pandemic period, } \\
\text { January } 5^{\text {th }}-\text { March } 29^{\text {th }} \\
2020\end{array}$ & $\begin{array}{l}\text { Pandemic period, } \\
\text { March } 30^{\text {th }}-\text { May } 16^{\text {th }} \\
2020\end{array}$ & $\begin{array}{l}\text { Relative reduction, } \\
\text { comparing pandemic } \\
\text { period with historical } \\
\text { control }\end{array}$ \\
\hline $\begin{array}{l}\text { Outpatient visits, } \\
\text { weekly mean } \\
\text { of patients }\end{array}$ & 1933 & 1845 & 165 & $-91.5 \%$ \\
\hline $\begin{array}{l}\text { Hospitalizations, } \\
\text { weekly mean } \\
\text { of patients }\end{array}$ & 132 & 108 & 45 & $-65.0 \%$ \\
\hline $\begin{array}{l}\text { Cardiovascular ICU } \\
\text { occupation, weekly } \\
\text { mean percent }\end{array}$ & $112 \%$ & $107 \%$ & $73 \%$ & $-34.9 \%$ \\
\hline $\begin{array}{l}\text { COVID-19 ICU } \\
\text { occupation, weekly } \\
\text { mean percent. }\end{array}$ & $\mathrm{n} / \mathrm{a}$ & $\mathrm{n} / \mathrm{a}$ & $98 \%$ & $\mathrm{n} / \mathrm{a}$ \\
\hline
\end{tabular}

ICU: intensive care unit; n/a: not available (COVID-19 attention at the study centre began on April $1^{\text {st }}, 2020$ ).

phenomenon is likely to occur in other hospitals, both nationally and internationally, particularly in hospitals that have changed their scope of attention to receive COVID-19 patients. Actions to improve timely access and care of patients with cardiovascular emergencies during the COVID-19 pandemic is urgently needed.

\section{REFERENCES}

1. De Filippo O, D'Ascenzo F, Angelini F, Bocchino PP, Conrotto F, Saglietto A, et al. Reduced rate of hospital admissions for ACS during covid-19 outbreak in Northern Italy. N Engl J Med. 2020; 383:88-9

2. Tam CF, Cheung KS, Lam S, Wong A, Yung A, Sze M, et al. Impact of Coronavirus disease 2019 (COVID-19) outbreak on ST-segment-elevation myocardial infarction care in Hong Kong, China. Circ Cardiovasc Qual Outcomes. 2020;13:e006631.

3. Garcia S, Albaghdadi MS, Meraj PM, Schmidt C, Garberich R, Jaffer FA, et al. Reduction in ST-segment elevation cardiac catheterization laboratory activations in the United States during COVID-19 pandemic. J Am Coll Cardiol. 2020;75:2871-2.

4. Schull MJ, Stukel TA, Vermeulen MJ, Zwarenstein M, Alter DA Manuel DG, et al. Effect of widespread restrictions on the use of hospital services during an outbreak of severe acute respiratory syndrome. CMAJ. 2007;176:1827-32.

5. ICES Utilization of Ontario's Health System During the 2003 SARS Outbreak. Available from: https://www.ices.on.ca/Publications/Atlases-and-Reports/2004/Utilization-of-Ontarioshealth-system. [Last accessed on 2020 May 01]. 